\title{
APPLICATIONS OF FUZZY DECISION MAKING FOR PERSONNEL SELECTION PROBLEM - A REVIEW
}

\author{
UDC: $005.962:[005.311 .6: 510.644$ \\ Review Scientific Paper \\ Ali Reza AFSHARI ${ }^{1}$, Milan NIKOLIĆ ${ }^{2}$, Dragan ĆOĆKALO ${ }^{2}$ \\ ${ }^{1}$ Department of Industrial Engineering, Shirvan Branch, Islamic Azad University, Shirvan, Iran. \\ E-mail: afshari@mshdiau.ac.ir \\ ${ }^{2}$ University of Novi Sad, Technical faculty “Mihajlo Pupin” Zrenjanin, 23000 Zrenjanin, Đure Đakovića bb, \\ Republic of Serbia
}

Paper received: 03.07.2014.; Paper accepted: 03.09.2014.

\begin{abstract}
Personnel selection determines the input quality of personnel, therefore, plays a decisive role in human resource management. Personnel selection problem has been studied extensively. Selecting the best personnel among many alternatives is a multi-criteria decision making (MCDM) problem. The necessity of dealing with uncertainty in real world problems has been a long-term research challenge that has originated different methodologies and theories. Fuzzy decision making along with their extensions have provided a wide range of tools that are able to deal with uncertainty in different types of problems. Fuzzy decision making methods have become increasingly popular in decision making for personnel selection. Various decision making approaches have been proposed to solve the problem. This paper presents a comprehensive literature review of the applying Fuzzy decision making techniques in personnel selection problem.
\end{abstract}

Key words: personnel selection, fuzzy decision making, multi criteria decision making.

\section{INTRODUCTION}

One of the most important parts of human resources management is Personnel selection. The input quality of personnel relates to personnel selection (Chien and Chen, 2008). When the candidates applies for specific jobs in the organization, basic purpose of personnel selection operations is determining those who have the necessary knowledge, skill, and ability to perform the needs of the job successfully (Kaynak, 2002). One of the well known methods of decision making is multi criteria decision making (MCDM) that can be used for personnel selection process. Most of the contributors applied the analytic hierarchy process (AHP), analytic network process (ANP), technique for order preference by similarity to ideal solutions (TOPSIS), fuzzy set theory, expert systems (ES), and their hybrids.

There are some articles that have reviewed the literature related to personnel selection (Robertson and Smith, 2001; Sackett and Lievens, 2008). This paper focuses on the fuzzy personnel selection problem approaches through a literature review and classification of the international journal articles from 1990 to 2014. Furthermore, this study covers fuzzy MCDM that are becoming popular methods in some application areas of classical MCDM. The literature review was done by an extensive search on such academic databases as Science Direct, Emerald, EBSCO, IEEE, Springer, Taylor \& Francis, and Wiley-Blackwell. This study aimed to address the following research questions:

1. Which approaches were prevalently applied?

2. Which evaluating criteria were paid more attention to?

3. Is there any inadequacy of the approaches?

The objective of this paper is to review the research work done in the field of Personnel selection. However, the scope of this review is limited to the literatures that suggest fuzzy decision making methodology to assist decision makers in evaluating and selecting personnel. This paper analyses the trend of personnel selection researches, discusses the most prevalently used approaches, and finds out the advantages and 
limitations of the methods. Final section concludes with the inferences of the undertaken research.

\section{PERSONNEL SELECTION AS A DECISION MAKING PROCESS}

Identifying, weighing, and evaluating the candidates against job requirements can be assumed as function of personnel selection. Personnel ability such as knowledge, skill and experience play an important role of organizations success. It is very difficult to correct the consequences from the wrong decision about hiring one person (Liao and Chang, 2009). One of the main targets of organization is that search for more powerful ways of evaluating and ranking of a set of personnel who have been evaluated in terms of different competencies. In literature, we can see that the attention was given to the selection of suitable person among candidates (alternatives) and extensively presented review can be found in Robertson and Smith (2001). A positive contribution to organizational performance can be result when, personnel selection strategies are aligned with the organization's strategies (Stone, 2002). Organizations spend a lot of time on hiring people. Too much time and cost will be spent on engaging, training, and firing of poor or disappointing employees, and the costs increase the longer it takes to realize that an employee is inadequate. For this reason, more than one person is required to evaluate and select an effective employee (Golec and Kahya, 2007). Traditional personnel selection method uses an experimental and statistical techniques approach. After using the experimental approach, decision makers with their experience and understanding of the job specifications, select personnel. In the statistical techniques approach decision makers get decision through the arrangement of test scores and the measure of accomplishment for the candidate. Interview with related candidates is one of the techniques concerning the personnel selection. Robertson and Smith (2001) present notable ability and availability of interviews to predict the performance of the personnel for the job. For making a better personnel selection decisions in organizations, there are a number of studies in literature. These studies are based on interviews, work sample tests, assessment centers, resumes, job knowledge tests, and personality tests in human resource management (Chien and Chen, 2008), while multi criteria decision making (MCDM) techniques are used by only a few of them (Dursun and Karsak, 2010).
The purpose of Personnel selection is to put the right persons in the right job position and this is a complex decision making process. A formal, systematic and rational selection model is needed for personnel selection process. Personnel selection process, first of all, based on job position must determine which criteria are to be the basis of evaluation. Also the importance (weights) of each criterion must be determined. Each criterion has a different importance, or maybe different decision makers have different importance for one criterion. Therefore, in personnel selections may occur error with selection tools that they are not based upon certain criteria (Dagdeviren and Ydksel, 2007). A familiar division of decision making is Multi Criteria Decision Making (MCDM). It deals with decision problems related to the presence of a number of decision criteria and it is a branch of operations research models. This major class of models is very often called MCDM and divided into multi attribute decision making (MADM) and multi objective decision making (MODM). Each of the above categories consists of several methods. Each method can also be classified as deterministic, stochastic and fuzzy methods with its own characteristics. Sometimes researchers may use combinations of the above methods. The methods can be classified as single or group decision making methods in the base of the number of decision makers (Pohekar and Ramachandran, 2004). Most of the contributors applied the AHP, ANP, TOPSIS and Expert Systems in personnel selection.

\section{FUZZY ENVIRONMENT DECISION MAKING}

The Decision Makers have difficulties in assigning crisp values as scorings to the criteria, because Personnel Selection is a human resource management problem. The main characteristic of personnel selection problem is the fuzziness. Some of the researchers extend the typical MCDM methods to the fuzzy environment in personnel selection. In order to represent the scorings of the alternatives or the importance of criteria in fuzzy sentence, there is a significant volume of studies that extend AHP and TOPSIS to the fuzzy environment (Kelemenis and Askounis, 2010).

\section{Fuzzy linguistic evaluation}

When decision makers do not want or are not able to represent their preferences in form of quantitative evaluations, Fuzzy Linguistic modeling can be used for qualitative evaluations. 
In fuzzy linguistic modeling we use linguistic variables (Siler and Buckley, 2005) whose values are words or sentences (not numbers). For example, in personnel selection, communication skill is a criterion that can be considered as a linguistic variable. Its linguistic values are poor, fair, good. By a fuzzy triangular number each linguistic value can be represented. Some authors used fuzzy linguistic variables or fuzzy linguistic rules for personnel selection.

Liang and Wang (1992) presented a model by using concepts of fuzzy set theory assess personnel fitness and job vacation. The degree of matching between personnel and job is expressed by fuzzy variables. The model consists of two levels. In the first level decision makers determine the criteria for personnel evaluation. In the second level under each evaluation criterion assigns fuzzy ratings to different personnel. Liang and Wang's approach was a start for using fuzzy theory to optimal personnel placement. On the other hand, fuzzy sets decision theory suggested with Alliger et al. (1993) for the personnel selection problem. Liang and Wang (1994) developed a fuzzy MCDM methodology to find the final ranking values for candidates in personnel selection problem. They defined criteria, such as personality, leadership, and past experience, general aptitude, and comprehension. They transferred the linguistic assessments about criteria weightings and ratings to the triangular fuzzy numbers (TFNs). Yaakob and Kawata (1999) by using fuzzy methodology studied workers' placement problem. By using the concept of fuzzy linguistic variables and fuzzy triangular numbers (TFNs) they did evaluation in industrial environment. For finding the better worker for production line they consider criteria as: Speed, Quality, Leadership, Professional knowledge, and Self-confidence. To rank the order of candidate approximately, the centre values of TFNs were used.

Lovrich (2000) used fuzzy linguistic model for personnel selection. He suggested using spreadsheet for implementing the model. Very high, high, average, low and very low are values of a linguistic variable. In a case study senior economic and financial analyst selection for the corporate unit of the telephone company was done with this model. Capaldo and Zollo (2001) presented a model based on a case study in FIAT Research Centre (CRF) that is a major Italian company. They tried to find decision formulations and decision samples to be used on the basis of the evaluation method adopted by the companies.
Then by using fuzzy logic they developed an evaluation method. Personnel selection criteria in this study were in three groups: professional skills, managerial skills, and personal characteristics. Butkiewicz (2002) used fuzzy numbers for staff selection. Staff selection in a tourism agency was done as numerical example in this study to show validity of the model. Criteria were included: Education, working knowledge, geographical knowledge, apparition, computer skills, knowhow of office equipment, serenity. Chen and Cheng (2005) combined Group decision support system (GDSS) with MCDM in fuzzy environment to solve the personnel selection problem. Their method used for information system project manager selection. The assessment of candidate and the important weights of criteria are given in linguistic terms and then transfer to triangular fuzzy numbers (TFNs). They proposed a new approach to rank fuzzy numbers by metric distance. They gave two examples to compare with other methods for showing their method has a good ranking method. A computer based group decision support system, FMCGDSS, to increase the recruiting productivity and to easily compare their method with other fuzzy number ranking methods. Golec and Kahya (2007) developed a hierarchical structure and use a fuzzy model for personnel selection. The model selects the personnel using the fuzzy rule base approach. Criteria had to representing organization's goals. In this paper a criteria hierarchy with three level developed and linguistic terms for rating includes: poor, fair, average, good and superior. Unimportant, Less important, Important, More important and Most important are the values of linguistic variable, named "Importance".

Balezentis et al. (2012) extended the fuzzy MULTIMOORA for linguistic reasoning under group decision making for personnel selection problem. Yu et al. (2013) explored aggregation methods for prioritized hesitant fuzzy elements and their application on personnel evaluation.

\section{Fuzzy expert systems}

Drigas et al. (2004) developed a hybrid expert system for personnel selection. For evaluation of the unemployed candidate for a certain job position, they used Neuro Fuzzy techniques that consider a corporate database of unemployed and enterprises profile data. For selecting an unemployed for a job position, this paper uses a Sugeno Fuzzy inferences system. They used six criteria for making evaluation mark of the 
unemployed: Age, Education, Additional Education (Training), Previous Employment (Experience), Foreign Language (English) and Computer Knowledge. Rashidi et al. (2011) for choosing a qualified project manager, amalgamated fuzzy systems, ANNs, and Genetic algorithm.

\section{Fuzzy TOPSIS}

Chen (2000) combined the fuzzy TOPSIS method and group decision making for personnel selection. He uses linguistic variables for the evaluations of the alternatives versus the criteria. Also the weight of each criterion is described by the values of fuzzy linguistic variables. Then he transfers linguistic variables to triangular fuzzy numbers by creating the membership function for each of variables. A numerical example for hiring a system analysis engineer was showed to illustrate the fuzzy TOPSIS procedure of the proposed method. Five criteria include: emotional steadiness, oral communication skill, personality, past experience and self-confidence used with 3 decision maker in this example. Saghafian and Hejazi (2005) presented modified Fuzzy TOPSIS method in group MCDM environment for University professor hiring. Publications and researches, teaching skills, practical experiences in industries and corporations, past experiences in teaching, and teaching discipline were considered as selection criteria. Fuzzy linguistic variables were used for criteria importance and alternative rating in this study and then were transferred to fuzzy triangular numbers. Wang and Elhag (2006) combined Fuzzy TOPSIS method based on alpha level sets with nonlinear programming (NLP). As a numerical example they solved a personnel selection problem were taken from Chen (2000). They used fuzzy linguistic variables as criteria importance and candidate ratings in their model. Mahdavi et al. (2008) used Fuzzy TOPSIS in group MCDM environment. Fuzzy linguistic variables applied for the importance weight of each criterion and candidate rating in this study. System analyst selection in a software company was stated as numerical example in this model and selection criteria included: Emotional steadiness, oral communication skill, personality, past experience, and self-confidence. Polychroniou and Giannikos (2009) presented a fuzzy MCDM methodology based on Fuzzy TOPSIS for personnel selection to cover organizational positions. Criteria weights were expressed by means of a linguistic variable whose values are "Moderate", "High" and "Very High" importance. The method was applied by using data from a real case in the mortgages department of a Greek bank for credit officer selection. Decision makers identified eight criteria: experience in credit analysis; annual salary request; personality profile; leadership ability; communication skills; educational background; age; and knowledge of foreign languages.

Kelemenis and Askounis (2010) in MCDM background used Fuzzy TOPSIS for solving personnel selection problem. Their aim was to support the decision on IT professional selection. In a group decision making environment they suggested a criteria hierarchy which consists of soft skills (strategy formulation/strategic decision making, change management/change adaptability, communication/interpersonal skill, leadership, risk/crisis management) and technical skills (computer networks, software/software tools, databases, professional experience, educational background, emerging/new technologies) for IT professional selection problem. Criteria importance and candidate ratings evaluated by using fuzzy linguistic variables that transfer to Triangular Fuzzy Numbers (TFNs). Dursun and Karsak (2010) combined fuzzy linguistic with TOPSIS in MCDM environment and introduced a methodology for personnel selection. They used ordered weighted averaging (OWA) operator for aggregating in fuzzy background. For hiring an Industrial Engineer they use eight criteria include: Emotional steadiness, Leadership, Self-confidence, Oral communication skill, Personality, past experience, General aptitude and Comprehension. They used fuzzy linguistic variable for rating candidates and for criteria importance. Their method was done in group decision making environment. Boran et al. (2011) employed an intuitionistic fuzzy TOPSIS approach to select appropriate personnel from candidates when selecting a sales manager at a manufacturing company. Finally Kelemenis et al. (2011) for manger selection suggested using Fuzzy TOPSIS. They employed fuzzy triangular number with linguistic variables for modeling criteria importance and candidate ratings. An empirical application was done in this research for hiring a middle level manager in group decision making background. The evaluation criteria were defined consisting of ten "soft" managerial skills and two "technical" skills.

\section{Fuzzy Multiple Objective Programming}

Karasak (2000) presented a fuzzy multiple objective Boolean linear programming methods for 
personnel selection. Objectives in this model were: Personality assessment, Leadership excellence, Excellence in oral communication skills, past experience, Computer skills, Fluency in foreign language, Aptitude test score, and Annual salary request. He used the values of linguistic variables such as: poor, fair, good and very good and defined triangular membership function for them. Karsak (2001) presented a fuzzy MCDM framework for selecting the most appropriate candidate. This work presented based on the concepts of ideal and anti-ideal solutions for the personnel selection. He evaluated qualitative and quantitative factors together via membership functions and then by using fuzzy multiple criteria programming modeled personnel selection problem. Baykasoglu et al. (2007) combined Fuzzy multiple objective mathematical programming with simulated annealing for project team selection problem. They used fuzzy concept like triangular fuzzy numbers and linguistic variables. In this fuzzy multiple objective optimization model, they considered fuzzy objectives and crisp constraints. To solve the proposed fuzzy optimization model, a simulated annealing algorithm was developed and software based on $\mathrm{C}++$ programming language presented. The team selection criteria described by four skills: Oral communication skills, technical expertise, problem solving ability, and decision making skills.

\section{Fuzzy analytical hierarchy process (AHP)}

Lazarevic (2001) combined fuzzy logic with AHP for minimizing subjective judgment in the process of personnel selection. Linguistic fuzzy variables were used in the model as the main decision elements. The model consists of an AHP of three levels. In the main decision criteria are supported by fuzzy linguistic variables for the preliminary selection. The model is illustrated by a case study for selecting a senior economic and financial analyst for an $\mathrm{ABC}$ telephone company. They purposed a criteria hierarchy in two levels. Huang et al. (2004) combined Fuzzy AHP, Fuzzy Neural Networks, and simple additive weighting (SAW) method for middle manager selection problem. The criteria in this paper were included: Capability trait, motivational trait, personality trait, conceptual skill, interpersonal skill, and technical skill. Fuzzy TECH software (www.fuzzytech.com) used in this study. Chen (2009) applied Fuzzy AHP in a MCDM environment for employ recruitment. He used questionnaire for building criteria hierarchy. Fuzzy linguistic variables used in this model and then transferred to fuzzy triangular number in Fuzzy AHP method. Gungor et al. (2009) for solving personnel selection problem used fuzzy analytical hierarchy process (FAHP). For helping managers make better decisions in fuzzy environment the authors introduce a practical computer-based decision support system. They converted all pair wise comparisons into triangular fuzzy numbers to adjust fuzzy rating and fuzzy attribute weight, and used fuzzy operators to get to select the best alternative. They compared the results with FAHP method and proposed Yager's weighted method. Pant et al. (2014) defined a methodology based on Delphi method as well as Fuzzy Analytic Hierarchy Process for personnel selection.

\section{Fuzzy analytical network process (ANP)}

Ayub et al. (2009) solved personnel selection problem in fuzzy environment with Fuzzy ANP method. As a numerical example they solved a personnel selection problem taken from Dagdeviren and Ydksel (2007). Lin (2010) combined ANP with Fuzzy DEA for solving personnel selection problem in group decision making (GDM) environment. He used linguistic variables for rating the applicants, ANP for determining the global weights of criteria, and Fuzzy DEA for final aggregation. With a numerical example for selecting an electrical engineer, he showed the validity of his model.

\section{Fuzzy ELECTRE}

Rouyendegh and Erkan (2012) used fuzzy ELECTRE algorithm for academic staff selection with using the opinion of experts applied into a model of group decision making. There were ten qualitative criteria for selecting the best candidate amongst five prospective applications.

\section{Fuzzy OWA}

Canós and Liern (2008) combined Fuzzy with ordered weighted average (OWA) aggregation operators for personnel selection problem. They developed a decision support system (DSS) to help managers for selecting decision making. Two personnel selection models presented in this study. Crisp OWA operators and a fuzzy parametric aggregation model were shown with a numerical example. 


\section{Other fuzzy integrated method}

Celik et al. (2009) combined Fuzzy AHP and Fuzzy TOPSIS for academic personnel selection. Fuzzy integrated multi-stages evaluation model (FIMEM) suggested for academic personnel selection. The FIMEM consists of fuzzy analytic hierarchy process (FAHP) for calculating the criteria weights and fuzzy technique for order preference by similarity to ideal solution (Fuzzy TOPSIS) to determine the final ranking of the candidates under multiple criteria. Recruitment of senior lecturer is proposed as a case study in this paper. The decision hierarchy of senior lecturer selection problem is structured based on 22 evaluation criteria. The committee members as decision makers used the linguistic variable including: very poor, poor, fair, good, and very good to express their opinions about the rating of each candidate regarding each performance criteria. Chen-Tung et al. (2009) for personnel selection used fuzzy linguistic PROMETHEE (Preference Ranking Organization Method for Enrichment Evaluation) method. They used crisp value and linguistic value together for alternative evaluation. In a group decision making environment they show validity of their model with a numerical example for marketing manager selection. They considered English ability and experience as two quantity criteria, and market ability and communication ability as two quality criteria. Unique task of sniper selection as a subset of personnel selection was performed by applying fuzzy ANP, fuzzy TOPSIS and fuzzy ELECTRE technique by Kabak et al. (2012). Saad et al. (2014) have presented an approach of handling personnel selection process by using the Hamming distance method. Based on the fact that most of criteria assessment are in qualitative or in subjective measurement, fuzzy set theory has been applied to overcome this limitation. Keršulienè and Turskis (2014) developed a decision making approach for Selection of a Chief Accounting Officer, which enables the incorporation of both crisp data and fuzzy data represented as linguistic variables or triangular fuzzy numbers into the analysis.

\section{OBSERVATIONS}

In this paper, 41 articles, were collected that appeared in the period from 1992 to 2014. They used Fuzzy decision making approaches for solving the personnel selection problem. The methods have been summarized in Table 2. Some observations based on these review are made in the following paragraphs.

\section{Application areas}

Table1. categorizes articles according to application areas. This problem, from the multi criteria perspective, which has attracted the interest of many scholars in different areas includes: nurse manager selection, doctoral student selection, officer selection, dean selection, financial analyst selection, division director, worker, system analysis engineer, staff, Insurance sales agents selection, scholarship student selection, manager Selection, postgraduate admissions officer, project manager, university professor, internal auditor, sales representative, political prognostics, intelligent selection, project team members, senior lecturer, marketing manager, televised sportscasters for the Olympic Games, R\&D personnel, credit officer, electronics engineer selection, industrial engineer.

\section{Most popular method applied}

The first objective of this review paper is to find the most popular approach applied in personnel selection problem literature. According to Table 2 the most popular methods are Fuzzy decision making along with TOPSIS, AHP, ANP, and ES. Fuzzy TOPSIS due to its simplicity ease of use, and great flexibility, has attracted more attention. In the past, it was used based on numerical data only. As the personnel selection problem involves both qualitative and quantitative criteria, MCDM methods have been modified to handle qualitative data, by Fuzzy MCDM.

\section{Selection criteria}

Another objective of this paper was to investigate about selection criteria. The most of the scholars presented empirical application or case study for showing the applicability of their models (Table 3). They formed a committee consist of experts for determining selection criteria based of job position. Tree systematic method for criteria selection also used include: Delphi method (Tavana, Kennedy, and Joglekar, 1996), NGT (Shih, Huang, and Shyur, 2005) and brainstorming (Jereb, Rajkovic, and Rajkovic, 2005). There are 20 papers that applied their method to simple numerical example. Therefore they do not valid their methods in real life. Yeh (2003) and Liao and Cheng (2009, 2009a) used interviewing for criteria selection. 
Table 1: Application and characteristic of papers

\begin{tabular}{|c|c|c|c|c|}
\hline Citation & Application & 方 & 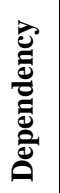 & 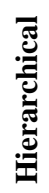 \\
\hline (Liang and Wang, 1992) & Personnel placement & & & \\
\hline (Liang and Wang, 1994) & Personnel Selection & & & \\
\hline (Yaakob and Kawata, 1999) & Finding the better worker for production line & & & \\
\hline (Ertugrul Karsak, 2000) & Personnel Selection for an expatriate position & & & \\
\hline (Lovrich, 2000) & Senior economic and financial analyst selection & & & \\
\hline (Chen, 2000) & System analysis engineer selection in a software company & $\bullet$ & & \\
\hline (Karsak, 2001) & Personnel Selection & & & \\
\hline (Capaldo and Zollo, 2001) & Personnel Selection & & & $\bullet$ \\
\hline (Lazarevic, 2001) & Senior economic and financial analyst & & & $\bullet$ \\
\hline (Butkiewicz, 2002) & Staff selection in a tourism agency & & & \\
\hline (Huang, et al., 2004) & Middle manager Selection & & & $\bullet$ \\
\hline (Drigas, et al., 2004) & Unemployed Matching & & & \\
\hline (Chen and Cheng, 2005) & IS personnel for the position of a project manager & $\bullet$ & & $\bullet$ \\
\hline (Saghafian and Hejazi, 2005) & University professor hiring & $\bullet$ & & $\bullet$ \\
\hline (Wang and Elhag, 2006) & System analysis engineer selection in a software company & $\bullet$ & & \\
\hline (Golec and Kahya, 2007) & Employee evaluation and Selection & & & $\bullet$ \\
\hline (Baykasoglu, et al., 2007) & Project team members Selection & & & \\
\hline (Mahdavi, et al., 2008) & System analyst selection in a software company & $\bullet$ & & \\
\hline (Zavadskas et al., 2008) & Project manager selection & & & \\
\hline (Canós and Liern, 2008) & Personnel selection & & & \\
\hline (Celik, et al., 2009) & Recruitment of senior lecturer & & & $\bullet$ \\
\hline (Chen, 2009) & Select an overseas marketing manager & & & $\bullet$ \\
\hline (Güngör, et al., 2009) & New position personnel selection & & & $\bullet$ \\
\hline (Ayub, et al., 2009) & Personnel selection & & $\bullet$ & $\bullet$ \\
\hline (Dejiang, 2009) & RandD personnel selection & & & \\
\hline (Polychroniou and Giannikos, 2009) & Credit officer & $\bullet$ & & \\
\hline (Dursun and Karsak, 2010) & Industrial engineer & $\bullet$ & & \\
\hline (Kelemenis and Askounis, 2010) & Top management team member & $\bullet$ & & $\bullet$ \\
\hline (Kelemenis, et al., 2011) & Manger selection & $\bullet$ & & $\bullet$ \\
\hline (Boran, et al., 2011) & Selecting a sales manager at a manufacturing company & $\bullet$ & & \\
\hline (Abbas Rashidi, et al., 2011) & Selection of Construction Project Managers & $\bullet$ & & \\
\hline (Zhang and Liu, 2011) & Hire a system analysis engineer & $\bullet$ & & \\
\hline (Kabak, et al., 2012) & Sniper selection & $\bullet$ & $\bullet$ & \\
\hline (Rouyendegh and Erkan, 2012) & Academic Staff Selection & $\bullet$ & & \\
\hline (Safarzadegan Gilan et al., 2012) & Selection of project manager in construction companies & $\bullet$ & & $\bullet$ \\
\hline (Baležentis, et al., 2012) & Personnel selection: an empirical application & $\bullet$ & & \\
\hline (Yu, et al., 2013) & Personnel selection & & & \\
\hline (Md Saad, et al., 2014) & Personnel selection in an academic institution & $\bullet$ & & \\
\hline (Violeta and Turskis, 2014) & Selection of a Chief Accounting Officer & $\bullet$ & & \\
\hline (Pant, et al., 2014) & Personnel selection & $\bullet$ & & \\
\hline
\end{tabular}

Table 2: MCDM methods used for personnel selection

\begin{tabular}{|l|l|}
\hline Fuzzy linguistic evaluation & 10 \\
\hline Fuzzy Multiple Objective Programming & 3 \\
\hline Fuzzy Expert System & 2 \\
\hline Fuzzy analytical hierarchy process (AHP) & 5 \\
\hline Fuzzy TOPSIS & 10 \\
\hline Fuzzy analytical network process (ANP) & 3 \\
\hline Fuzzy ELECTRE & 1 \\
\hline Fuzzy OWA & 1 \\
\hline Other fuzzy integrated method & 5 \\
\hline
\end{tabular}




\section{Limitations of approaches}

The last objective of this paper is to critically analyze the approaches, and try to find out some drawbacks:

1. Possible dependencies between the criteria in the personnel selection model being neglected in the most of the existing studies. In personnel selection model is not possible to assume that each criterion is independent from other criteria. Any criteria in the model could be related to, or dependent on other criteria. In personnel selection model, evaluating the dependencies between criteria should contribute to the objectivity of decisions. The considering dependency in Fuzzy MCDM can improve the quality of decision making process.

2. Group decision making (GDM) is a very important factor for a comprehensive solving of the problem. But it was not considered the group environment in the majority of the reviewed studies. The approach that considers one single DM does not have completeness while multi criteria decision making techniques are used. One of the critical tasks for an organization is Personnel selection; therefore, more rational decisions are made by a group of people rather than by a single person.

\section{CONCLUSION}

From the decision science point of view, many scholars have dealt with the personnel selection problem. To handle this decision making problem, they combined techniques from operational research with artificial intelligence fields. Expert systems, fuzzy linguistic variables, neural networks and multi criteria decision making techniques are used as methodology.

As a future steps to personnel selection problem:

1. Comparison of the proposed approach to other MADM methods such as Fuzzy Integral, VIKOR.

2. Situations should be studied, in which a group of decision makers, each one of different importance, are involved in the decision making process.

3. Developing hybrid methodology based on fuzzy linguistic, solving dependency and hierarchical structure for criteria.

4. Applying purposed methods to real world group decision making problems in diverse disciplines containing both crisp and fuzzy data together.

\section{REFERENCES}

Abbas Rashidi, S., Jazebi, F., \& Brilakis, I. (2011). Neurofuzzy Genetic System for Selection of Construction Project Managers. Journal of Construction Engineering and Management, 137, 17.

Alliger, G. M., Feinzig, S. L., \& Janak, E. A. (1993). Fuzzy sets and personnel selection: Discussion and an application. Journal of Occupational and Organizational Psychology, 66, 163-169.

Ayub, M., Kabir, M. J., \& Alam, M. G. R. (2009, 21-23 Dec. 2009). Personnel selection method using Analytic network Process (ANP) and fuzzy concept. Paper presented at the Computers and Information Technology, 2009. ICCIT '09. 12th International Conference on.

Baležentis, A., Baležentis, T., \& Brauers, W. K. (2012). Personnel selection based on computing with words and fuzzy MULTIMOORA. Expert Systems with Applications, 39(9), 7961-7967.

Baykasoglu, A., Dereli, T., \& Das, S. (2007). Project team selection using fuzzy optimization approach. Cybernetics and Systems, 38(2), 155-185.

Boran, F. E., Genç, S., \& Akay, D. (2011). Personnel selection based on intuitionistic fuzzy sets. Human Factors and Ergonomics in Manufacturing \& Service Industries, n/a-n/a.

Butkiewicz, B. S. (2002, 6-9 Oct. 2002). Selection of staff for enterprise using fuzzy logic. Paper presented at the Systems, Man and Cybernetics, 2002 IEEE International Conference on.

Canós, L., \& Liern, V. (2008). Soft computing-based aggregation methods for human resource management. European Journal of Operational Research, 189(3), 669-681.

Capaldo, G., \& Zollo, G. (2001). Applying fuzzy logic to personnel assessment: A case study. Omega, 29(6), 585-597.

Celik, M., Kandakoglu, A., \& Er, I. D. (2009). Structuring fuzzy integrated multi-stages evaluation model on academic personnel recruitment in MET institutions. Expert Systems with Applications, 36(3), 6918-6927.

Chen-Tung, C., Yuan-Chu, H., \& Wei-Zhan, H. (2009, 8-11 Dec. 2009). Applying multiple linguistic PROMETHEE method for personnel evaluation and selection. Paper presented at the Industrial Engineering and Engineering Management, 2009. IEEM 2009. IEEE International Conference on.

Chen, C. T. (2000). Extensions of the TOPSIS for group decision-making under fuzzy environment. Fuzzy Sets and Systems, 114(1), 1-9.

Chen, L. S., \& Cheng, C. H. (2005). Selecting IS personnel use fuzzy GDSS based on metric distance method. European Journal of Operational Research, 160(3 Spec. Iss.), 803-820.

Chen, P.-C. (2009). A Fuzzy Multiple Criteria Decision Making Model in Employee Recruitment. International Journal of Computer Science and Network Security, 9(7), 113-117. 
Chien, C. F., \& Chen, L. F. (2008). Data mining to improve personnel selection and enhance human capital: A case study in high-technology industry. Expert Systems with Applications, 34(1), 280-290.

Dagdeviren, M., \& Ydksel, D. (2007). Personnel Selection Using Analytic Network Process. Dstanbul Ticaret Universitesi Fen Bilimleri Dergisi Yil, 6(1), 99-118.

Dejiang, W. (2009, 20-22 Sept. 2009). Extension of TOPSIS Method for R\&D Personnel Selection Problem with Interval Grey Number. Paper presented at the Management and Service Science, 2009. MASS '09. International Conference on.

Drigas, A., Kouremenos, S., Vrettos, S., Vrettaros, J., \& Kouremenos, D. (2004). An expert system for job matching of the unemployed. Expert Systems with Applications, 26(2), 217-224.

Dursun, M., \& Karsak, E. E. (2010). A fuzzy MCDM approach for personnel selection. Expert Systems with Applications, 37(6), 4324-4330.

Ertugrul Karsak, E. (2000, 2000). A fuzzy multiple objective programming approach for personnel selection. Paper presented at the Systems, Man, and Cybernetics, 2000 IEEE International Conference on.

Golec, A., \& Kahya, E. (2007). A fuzzy model for competency-based employee evaluation and selection. Computers and Industrial Engineering, 52(1), 143-161.

Güngör, Z., Serhadlioğlu, G., \& Kesen, S. E. (2009). A fuzzy AHP approach to personnel selection problem. Applied Soft Computing Journal, 9(2), 641-646.

Huang, L. C., Huang, K. S., Huang, H. P., \& Jaw, B. S. (2004). Applying fuzzy neural network in human resource selection system.

Jereb, E., Rajkovic, U., \& Rajkovic, V. (2005). A hierarchical multi-attribute system approach to personnel selection. International Journal of Selection and Assessment, 13(3), 198-205.

Kabak, M., Burmaoğlu, S., \& Kazançoğlu, Y. (2012). A fuzzy hybrid MCDM approach for professional selection. Expert Systems with Applications, 39(3), 3516-3525.

Karsak, E. E. (2001). Personnel selection using a fuzzy MCDM approach based on ideal and anti-ideal solutions. Multiple Criteria Decision Making in the New Millenium, 425-432.

Kaynak, T. (2002). Human Resources Management. Istanbul: Nobel Yayınevi.

Kelemenis, A., \& Askounis, D. (2010). A new TOPSISbased multi-criteria approach to personnel selection. Expert Systems with Applications, 37(7), 4999-5008.

Kelemenis, A., Ergazakis, K., \& Askounis, D. (2011). Support managers' selection using an extension of fuzzy TOPSIS. Expert Systems with Applications, 38(3), 2774-2782.

Lazarevic, S. P. (2001). Personnel selection fuzzy model. International Transactions in Operational Research, 8(1), 89-105.

Liang, G. S., \& Wang, M. J. J. (1992). Personnel placement in a fuzzy environment. Computers and Operations Research, 19(2), 107-121.
Liang, G. S., \& Wang, M. J. J. (1994). Personnel selection using fuzzy MCDM algorithm. European Journal of Operational Research, 78(1), 22-33.

Liao, S. K., \& Chang, K. L. (2009). Selecting public relations personnel of hospitals by analytic network process. Journal of Hospital Marketing and Public Relations, 19(1), 52-63.

Liao, S. K., \& Chang, K. L. (2009a). Select televised sportscasters for Olympic games by analytic network process. Management Decision, 47(1), 1423.

Lin, H. T. (2010). Personnel selection using analytic network process and fuzzy data envelopment analysis approaches. Computers and Industrial Engineering, 59(4), 937-944.

Lovrich, M. (2000). A fuzzy approach to personnel selection. Proceedings of the Fifteenth European Meeting on Cybernetics and Systems Research, 234239.

Mahdavi, I., Mahdavi-Amiri, N., Heidarzade, A., \& Nourifar, R. (2008). Designing a model of fuzzy TOPSIS in multiple criteria decision making. Applied Mathematics and Computation, 206(2), 607617.

Md Saad, R., Ahmad, M., Abu, M., \& Jusoh, M. (2014). Hamming Distance Method with Subjective and Objective Weights for Personnel Selection. The Scientific World Journal, 2014.

Pant, M., Deep, K., Nagar, A., Bansal, J. C., \& Aggarwal, R. (2014). Identifying and Prioritizing Human Capital Measurement Indicators for Personnel Selection Using Fuzzy MADM Proceedings of the Third International Conference on Soft Computing for Problem Solving (Vol. 258, pp. 427-439): Springer India.

Pohekar, S. D., \& Ramachandran, M. (2004). Application of multi-criteria decision making to sustainable energy planning - A review. Renewable and Sustainable Energy Reviews, 8(4), 365-381.

Polychroniou, P. V., \& Giannikos, I. (2009). A fuzzy multicriteria decision-making methodology for selection of human resources in a Greek private bank. Career Development International, 14(4), 372-387.

Robertson, I. T., \& Smith, M. (2001). Personnel selection. Journal of Occupational and Organizational Psychology, 74(4), 441-472.

Rouyendegh, B. D., \& Erkan, T. E. (2012). An application of the fuzzy electre method for academic staff selection. Human Factors and Ergonomics in Manufacturing \& Service Industries.

Sackett, P. R., \& Lievens, F. (2008). Personnel selection. Annu. Rev. Psychol., 59, 419-450.

Safarzadegan Gilan, S., Sebt, M. H., \& Shahhosseini, V. (2012). Computing with words for hierarchical competency based selection of personnel in construction companies. Applied Soft Computing, 12(2), 860-871.

Saghafian, S., \& Hejazi, S. R. (2005). Multi-criteria group decision making using a modified fuzzy TOPSIS procedure. 
Shih, H. S., Huang, L. C., \& Shyur, H. J. (2005). Recruitment and selection processes through an effective GDSS. Computers and Mathematics with Applications, 50(10-12), 1543-1558.

Siler, W., \& Buckley, J. J. (2005). Fuzzy Expert Systems and Fuzzy Reasoning. Hoboken, New Jersey: John Wiley \& Sons.

Stone, R. S. (2002). Human resource management. Brisbane: John Wiley.

Tavana, M., Kennedy, D. T., \& Joglekar, P. (1996). A group decision support framework for consensus ranking of technical manager candidates. Omega, 24(5), 523-538.

Violeta, K. u., \& Turskis, Z. (2014). A hybrid linguistic fuzzy multiple criteria group selection of a chief accounting officer. Journal of Business Economics and Management, 15(2), 232-252.

Wang, Y. M., \& Elhag, T. M. S. (2006). Fuzzy TOPSIS method based on alpha level sets with an application to bridge risk assessment. Expert Systems with Applications, 31(2), 309-319.
Yaakob, S. B., \& Kawata, S. (1999). Workers' placement in an industrial environment. Fuzzy Sets and Systems, 106(3), 289-297.

Yeh, C. H. (2003). The selection of multiattribute decision making methods for scholarship student selection. International Journal of Selection and Assessment, 11(4), 289-296.

Yu, D., Zhang, W., \& Xu, Y. (2013). Group decision making under hesitant fuzzy environment with application to personnel evaluation. KnowledgeBased Systems, 52, 1-10.

Zavadskas, E. K., Turskis, Z., Tamošaitiene, J., \& Marina, V. (2008). Multicriteria selection of project managers by applying grey criteria. Technological and Economic Development of Economy, 14(4), 462-477.

Zhang, S.-f., \& Liu, S.-y. (2011). A GRA-based intuitionistic fuzzy multi-criteria group decision making method for personnel selection. Expert Systems with Applications, 38(9), 11401-11405. 